\title{
Relationship of Mandibular Third Molar to Mandibular Anterior Crowding
}

\author{
Ambika Sood ${ }^{1} \quad$ Mandeep Bhullar $^{1}$ Sanjay Mittal ${ }^{1}$ \\ ${ }^{1}$ Department of Orthodontics and Dentofacial Orthopedics, Bhojia \\ Dental College and Hospital, Baddi, Himachal Pradesh, India
}

Isha Aggarwal' Divya Singla' Abhishek Sharma ${ }^{1}$
Address for correspondence Ambika Sood, MDS III year, Department of Orthodontics and Dentofacial Orthopedics, Bhojia Dental College and Hospital, Baddi 173205, Himachal Pradesh, India (e-mail: ambika.92.sood@gmail.com).

Dent J Adv Stud 2018;6:89-96

\begin{abstract}
Keywords

- mandibular anterior crowding

- third molar eruption level

- third eruption space

- third molar angulation
\end{abstract}

Introduction The impact of third molars in occurrence of secondary mandibular incisor crowding has been a disputable subject and is reviewed in the dental literature for many years. The relationships between lower third molar angulation, eruption level, and eruption space to lower anterior crowding are not completely understood.

Aim To evaluate the relation between the third molar angulations, eruption space, eruption level, and mandibular anterior crowding.

Materials and Methods Pretreatment plaster study models (mandibular dental arches) and orthopantomograph of 40 individuals, aged between 12 and 22 years, were part of the study. The whole sample was divided into two groups based on the Little's index of irregularity: group I-control group $(n=20)$ composed of patients with index 0 to $3 \mathrm{~mm}$, and group II-study group $(n=20)$ composed of patients with index $>3 \mathrm{~mm}$. Calculations were made for the third molar eruption depth, eruption space, and angulation.

Statistical Analysis Mean values were compared for selected dimensions between the control and study groups with Student's $t$-test.

Results Statistically significant differences for Ganss ratio in right side between the control and study groups with a $p$-value of 0.049 were observed. Statistically insignificant difference was seen between the control and study groups for other parameters. Eruption level B was found for maximum molars in the study group, $95 \%$ on right and $85 \%$ on left side.

Conclusion It was inferred that no strong relation exists between the third molar eruption level, space, and angulations to mandibular anterior crowding.

\section{Introduction}

Human face and dental arches go through major changes during growth and adaptation to the environment. Rapid and relatively extensive changes occur during mixed dentition period and continue until appearance of all permanent teeth. Age-associated changes in the dental arches do not cease with commencement of adulthood but continue at a slower rate throughout adult life. ${ }^{1}$

The mandibular incisor crowding is an acclaimed problem, whose cause is obscured by its multifactorial nature. It has been a substance of debated discussion over the years. There are multiple factors contributing to it, in different people, at various stages of development, for example physiologic mesial drift, anterior component of force of occlusion, mesial vectors of muscular contraction, developing third molar, amount and direction of late mandibular growth, skeletal structure and complex growth patterns, soft tissue maturation, occlusal changes, tooth morphology, periodontal forces, path of eruption, and degenerative tissue changes, which may be involved. ${ }^{2}$
License terms

C2018 Bhojia Dental College an Hospital affiliated to Himachal Pradesh University 
For a long time, the third molar development and their interaction with the dentition has been of great concern to general dentists and dental specialists. Third molar is a tooth characterized by variability in the presence or absence in the oral cavity, time of its formation and calcification, its course of eruption and final position, and its crown and root morphology. Erupting third molars continually change their angular positions and show important preeruptive rotational movements. ${ }^{3}$ Radiographic appearance of starts as early as the age of 5 years and up to the age of 16 years, commonly erupting in the oral cavity between the ages of 18 and 24, and they present the highest rate of impaction.,4

Even though, third molars are not directly involved in orthodontic treatment in maximum cases, but in a few cases, they can influence the latter or be influenced by it. This indicates their direct influence in treatment planning. The impact of third molars in advancement of a late mandibular incisor crowding has been controversial for many years and has been discussed in the dental literature.

The intent of this study were, therefore, measurement of the mandibular anterior segment to evaluate potential third molar influence on lower incisor crowding and to find relations, if any, between mandibular anterior crowding and retromolar space/lower third molar crown width, eruption level, and molar angulation.

\section{Aims}

- To analyze the variation in the eruption space of mandibular third molars between patients showing minimal lower anterior crowding and patients with lower anterior crowding.

- To assess the eruption level of third molars between the patients showing minimal lower anterior crowding and patients with lower anterior crowding.

- To compare the angulations between third molar and second molar, occlusal plane (OP), and a horizontal reference plane (HRP) between the patients showing minimal lower anterior crowding and patients with lower anterior crowding.

\section{Materials and Methods}

This study was performed in the Department of Orthodontics and Dentofacial Orthopaedics, Bhojia Dental College Baddi, H.P. Pretreatment plaster study models (mandibular dental arches) and orthopantomograph of 40 patients (males $=11$, females $=29$ ) with ages varying between 12 and 22 years with mean age of 15.40 years, were included in this study. Only the patients fulfilling the following selection criteria were involved in the study.

\section{Inclusion Criteria}

- Full complement of teeth presents intraorally, irrespective of the third molars.

- Third molars should be present in the OPG (orthopantomograph).
- Minimal damage to tooth dimension by caries or attrition.

- Presence of crowding of 0 to $3 \mathrm{~mm}$ for control group and $>3 \mathrm{~mm}$ for study group in the mandibular anterior region as measured by Little's index of irregularity for study group.

\section{Exclusion Criteria}

- Absence of third molar.

- Presence of retained deciduous teeth, supernumerary teeth, etc.

- Presence of mandible asymmetries.

- Presence of large restorations, artificial teeth.

- Presence of skeletal disorders and abnormalities.

- Individuals who have had prior orthodontic treatment or orthognathic surgery.

- Individuals who were not willing to take part in the study.

Little's index of irregularity was measured for all the 40 patients, and based on the values obtained, the sample was divided into two groups ( - Table $\mathbf{1}$ ).

Table 1 Grouping of sample

\begin{tabular}{|l|l|}
\hline Group I (control group) & Group II (study group) \\
\hline $\begin{array}{l}\text { With Little's index of } \\
\text { irregularity of } 0-3 \mathrm{~mm}\end{array}$ & $\begin{array}{l}\text { Little's index of irregularity } \\
>3 \mathrm{~mm}\end{array}$ \\
\hline
\end{tabular}

\section{Assessment of Mandibular Anterior Crowding on Plaster Study Models}

On the dental plaster model, horizontal linear displacements from the anatomic contact points to contact point between lower canine, using a digital caliper was done, and summation of measurement was used for Little's index of irregularity calculation (-Fig. 1). ${ }^{5}$

Each cast was subjectively ranked on a scale ranging from 0 to 10 , using the following criteria ${ }^{5}$ :

- 0 Perfect alignmentr

- 1-3 Minimal irregularity

- 4-6 Moderate irregularity

- 7-9 Severe irregularity

- 10 Very severe irregularity

\section{Assessment of Third Molar Space, Level, and Angulation in OPG}

All tracings and measurements were done manually by the same operator. All the bilateral and unilateral landmarks

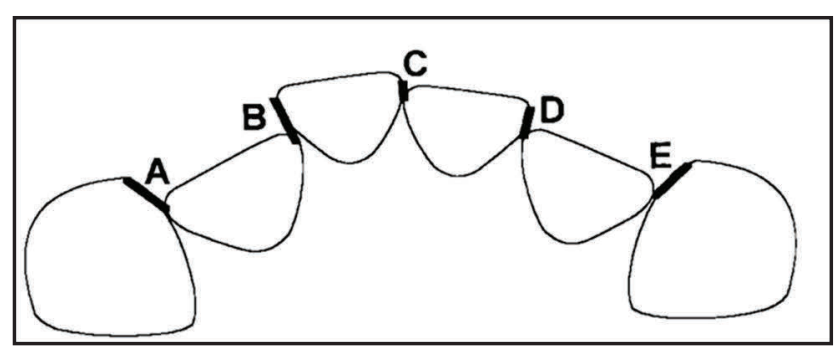

Fig. 1 Little's index of irregularity $(A+B+C+D+E)$. 
were identified and marked on the OPG and traced on matte acetate sheet, with a 0.5 -mm-diameter lead pencil and measurements were made. Measurements were done on both right $(\mathrm{R})$ and left $(\mathrm{L})$ sides.

\section{Landmarks Used in the Study}

Areas of the mandibular third molar (M3), mandibular second molar (M2), mandibular first premolar (P1), anterior border of ramus, nasal septum, and anterior nasal spine (ANS) on the OPG were traced ( - Fig. 2).

- Long axis of the second molar ${ }^{6}$ : It was drawn extending from the mid-occlusal point and midpoint of root bifurcation of the second molar.

- Long axes of the third molar buds ${ }^{7}$ : It was traced as the perpendicular bisector of a line connecting outlines of the most mesial and distal cervical areas.

- $\mathbf{O P}^{8}$ : It is the line joining the tips of most superior cusps of the first premolar and tip of most superior mesial cusp of the second molar. A perpendicular line touching the most distal point of the second molar crown was also drawn from OP.

- HRP $^{9}$ : Nasal septum and ANS were marked, and line joining them was traced and bisected. A perpendicular line to this midline bisector extending bilaterally through palatal shadow was drawn, termed as horizontal reference plane.

\section{Measurements Used in This Study}

\section{Linear Measurements Eruption Space ${ }^{8}$}

- Available space: It was measured as distance between intersection of OP with anterior border of ramus and intersection of line perpendicular to the OP from distal most aspect of second molar. (Line A)
- Third molar crown mesiodistal width: It is the length of the line connecting most mesial and distal outlines of third molar crown. (Line B)

- Ganss ratio: The ratio of line $A$ to $B$, that is, available space/third molar crown mesiodistal width ( - Fig. 3).

\section{Eruption Depth ${ }^{10}$}

Eruption level was calculated as depth of the third molar in relation to the neighboring second molar ( - Fig. 4). According to its eruption level, as suggested by Pell and Gregory, ${ }^{10}$ each third molar was assigned to one of the three groups. The highest portion of the third molar was on

- Level A (fully erupted) group: Same level as or above the OP of the adjacent second molar.

- Level B (partially erupted) group: Below the OP but above the cementoenamel junction (CEJ) of the second molar.

- Level C (unerupted) group: Beneath the CEJ of the second molar.

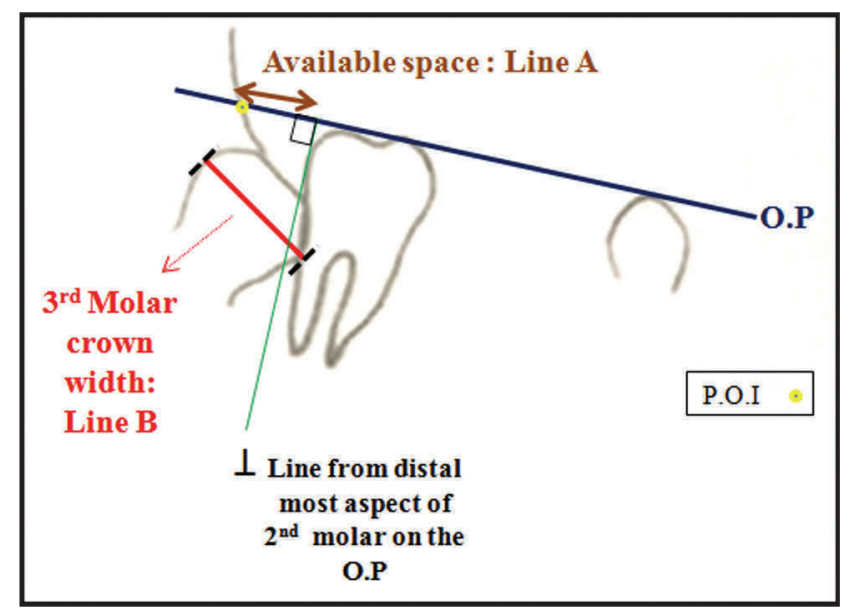

Fig. 3 Linear measurements. OP, occlusal plane; POI, point of intersection.

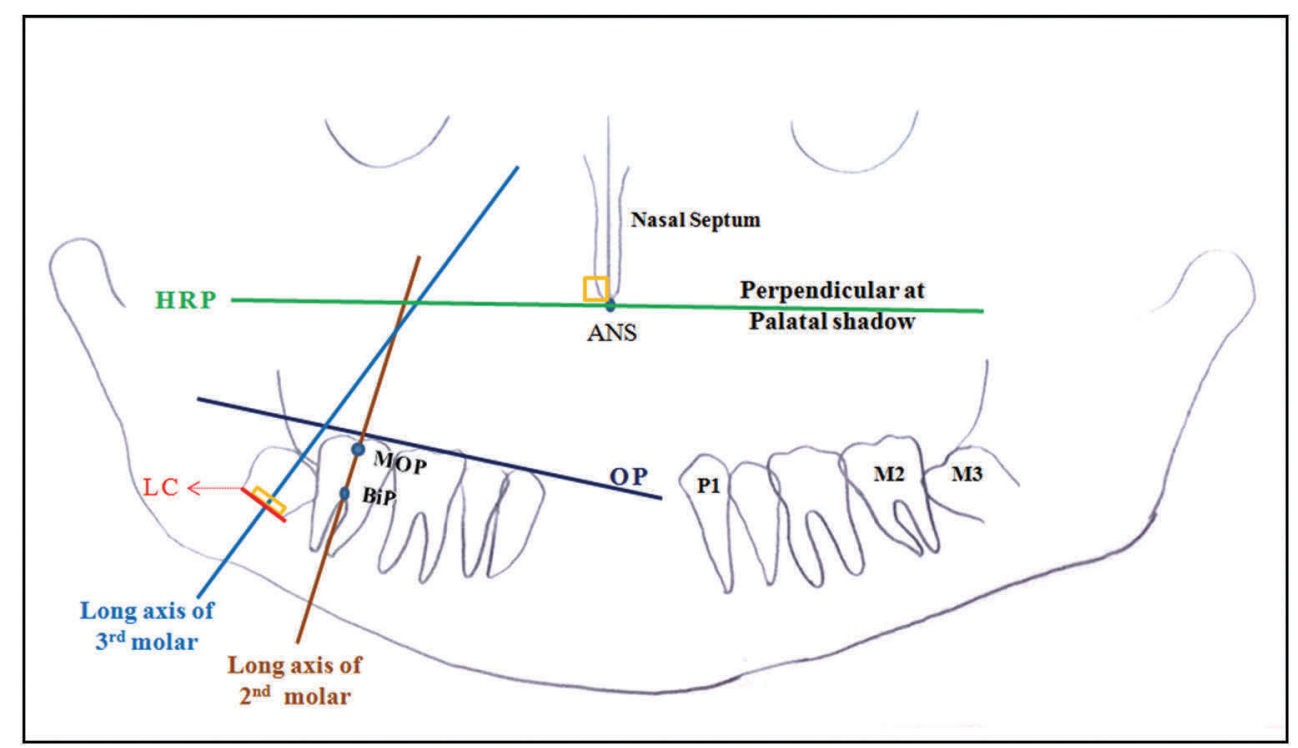

Fig. 2 Landmarks used in this study. ANS, anterior nasal spine; BiP, bifurcation point; HRP, horizontal reference plane; LC, line at cervical level of molar bud; MOP, mid-occlusal point; OP, occlusal plane. 


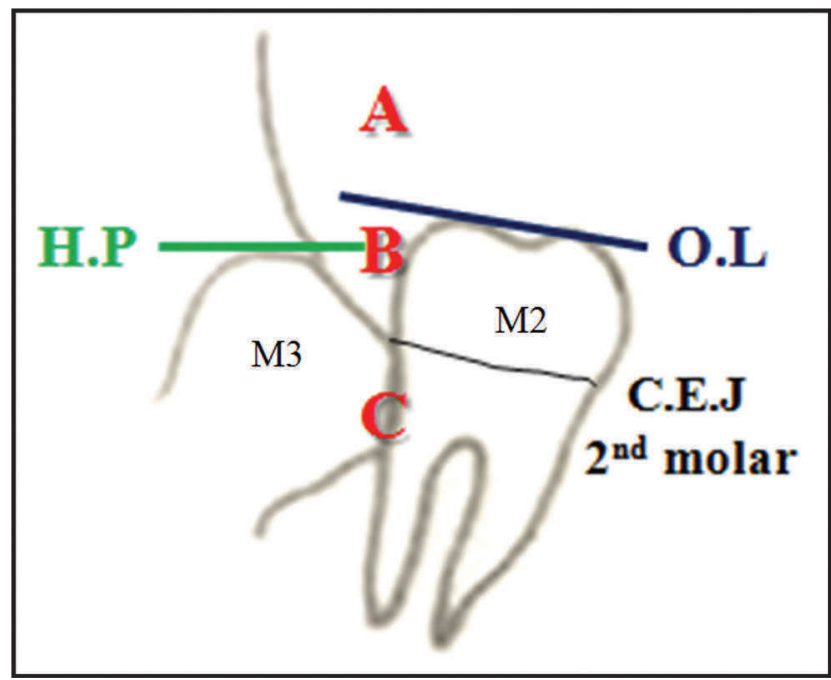

Fig. 4 Eruption depth: P\&G classification. HP, highest point of the third molar crown. A: M3 is on same level or above the occlusal plane. $\mathrm{B}$ : $\mathrm{M} 3$ is below the occlusal plane above CEJ of second molar. C: M3 is beneath the cementoenamel junction (CEJ) of the second molar.

\section{Angular Measurements}

- Third molar angulation with second molar ${ }^{6}$ : It is the angle formed by long axis of the mandibular third molar and long axis of the mandibular second molar.

- Third molar angulation with OP: It is the angle formed between OP and long axis of the third molar.

- Third molar angulation with HRP': It is measured by the angle formed between the HRP and long axis of the mandibular third molar (-Fig. 5).

\section{Statistical Analysis}

Values obtained for linear and angular measurements were subjected in IBM SPSS software (version 22 Armonk, NY). Mean and standard deviations were calculated for each parameter for each group.
Comparisons of mean values for various parameters selected for third molars between these control and study groups was made using the Student's $t$-test.

\section{Results}

This study was performed in 40 patients with age group of 12 to 22 years with mean age of 15.40 years. The sample was divided into two groups: control group $(n=20)$ without lower anterior crowding and the study group $(n=20)$ with lower anterior crowding of more than $3 \mathrm{~mm}$ on the basis of Little's index of irregularity.

The measurements were made for mandibular third molar space (Ganss ratio), eruption level, and molar angulation with second molar, OP, and a constructed HRP. Mean and standard deviation for the data were calculated and summarized in - Table 2. Comparison of parameters between the control and study groups were made using the Student's $t$-test, which showed a statistically significant difference in Ganss ratio of right side of the study group when compared with control group as depicted in - Table 3 .

\section{Ganss Ratio}

The mean value for Ganss ratio was greatest in the right side of control group $(0.763 \pm 0.354)$, followed by left side of control group $(0.7170 \pm 0.252)$ and then in left side of study group $(0.673 \mathrm{~mm} \pm 0.227)$, with lowest mean on right side of study group $(0.570 \pm 0.232)$. Results showed statistically significant difference for Ganss ratio between the control and study groups in the right side with a $p$ value of 0.049 (-Tables 2, 3).

\section{Third Molar Angulation with Second Molar}

The mean value for third molar angulation with second molar was greatest in right side of control group $(29.95 \pm 24.676)$, followed by left side of study group $(29.55 \pm 12.107)$ and then in right side of study group $(26.40 \pm 10.850)$. The lowest was found in the left side of control group (24.73 \pm 22.86$)$.

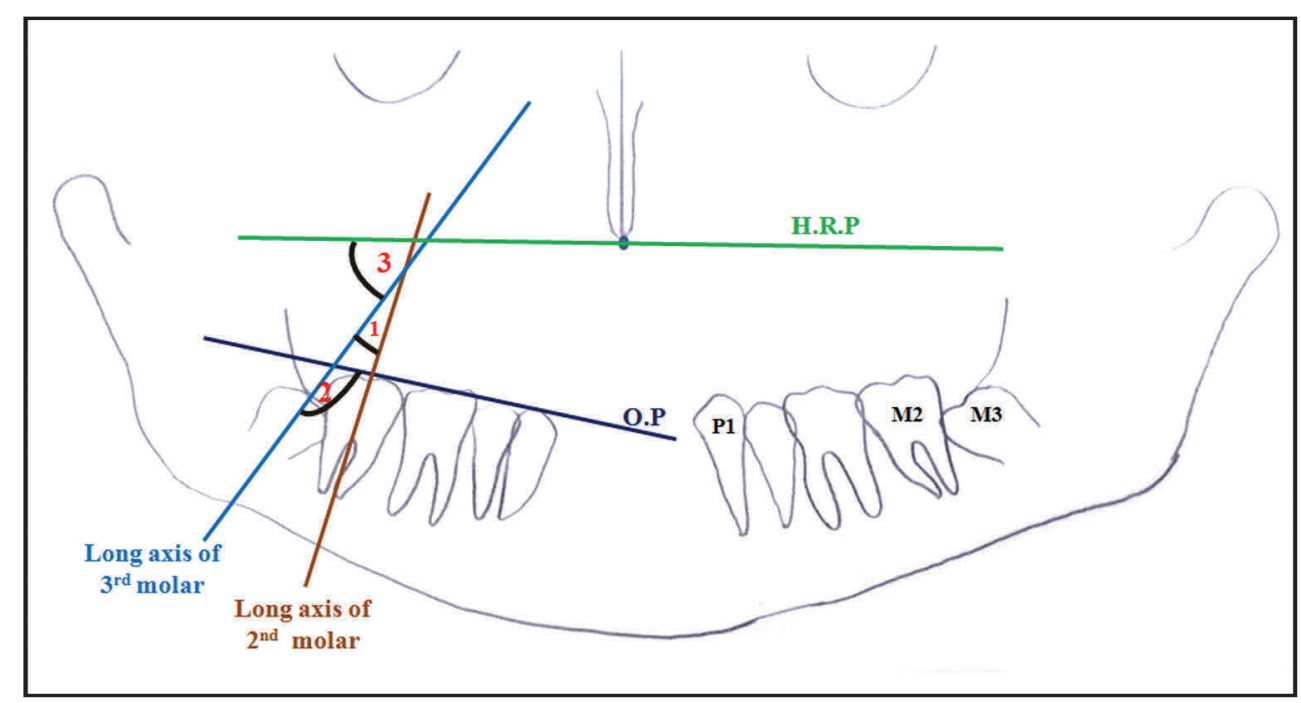

Fig. 5 Angular measurements. 1: third molar angulation with second molar; 2: third molar angulation with occlusal plane (OP); 3: third molar angulation with horizontal reference plane (HRP). 
Table 2 Descriptive statistics showing mean and standard deviation of mandibular third molar space (Ganss ratio) and its angulation with second molar, angulation with occlusal plane, and angulation with HRP in control and study groups

\begin{tabular}{|l|l|l|l|l|}
\hline \multirow{2}{*}{ Parameters } & \multicolumn{2}{|c|}{ Control $(n=20)$} & \multicolumn{2}{c|}{ Study $(n=20)$} \\
\cline { 2 - 5 } & Mean \pm SD & $\begin{array}{l}\text { Standard error } \\
\text { mean }\end{array}$ & Mean \pm SD & \multicolumn{2}{l|}{$\begin{array}{l}\text { Standard error } \\
\text { mean }\end{array}$} \\
\hline Ganss ratio, left & $0.717 \pm 0.252$ & 0.05641 & $0.6735 \pm 0.227$ & 0.05085 \\
\hline 3rd to 2nd molar (angle), left & $24.73 \pm .864$ & 5.112 & $29.55 \pm 12.107$ & 2.707 \\
\hline 3rd molar to occlusal plane (angle), left & $120.85 \pm 17.977$ & 4.020 & $122.95 \pm 11.157$ & 2.495 \\
\hline 3rd molar to HRP (angle), left & $45.275 \pm 20.596$ & 4.6056 & $39.550 \pm 12.705$ & 2.8409 \\
\hline Ganss ratio, right & $0.763 \pm 0.354$ & 0.0792 & $0.570 \pm 0.232$ & 0.0519 \\
\hline 3rd to 2nd molar (angle), right & $29.95 \pm 24.676$ & 5.518 & $26.40 \pm 10.850$ & 2.426 \\
\hline 3rd molar to occlusal plane (angle), right & $116.90 \pm 31.993$ & 7.154 & $122.35 \pm 11.070$ & 2.475 \\
\hline 3rd molar to HRP (angle), right & $42.68 \pm 21.331$ & 4.770 & $44.00 \pm 13.083$ & 2.925 \\
\hline
\end{tabular}

Abbreviations: HRP, horizontal reference plane; SD, standard deviation.

Table 3 Mean values comparison for dimensions among control and study groups using Student's t-test

\begin{tabular}{|l|l|l|l|l|}
\hline \multicolumn{5}{|c|}{$t$-test for equality of means } \\
\hline Parameters & $t$ & Df & Sig. (2-tailed) & Mean difference \pm Standard error difference \\
\hline Ganss ratio, left & 0.573 & 38 & 0.570 & $0.043 \pm 0.0759$ \\
\hline 3rd to 2nd molar (angle), left & -0.834 & 38 & 0.409 & $-4.825 \pm 5.785$ \\
\hline 3rd molar to occlusal plane (angle), left & -0.444 & 38 & 0.660 & $-2.100 \pm 4.731$ \\
\hline 3rd molar to HRP (angle) left & 1.058 & 38 & 0.297 & $5.725 \pm 5.411$ \\
\hline Ganss ratio, right & 2.038 & 38 & $\mathbf{0 . 0 4 9}$ & $0.193 \pm 0.094$ \\
\hline 3rd to 2nd molar (angle), right & 0.589 & 38 & 0.559 & $3.550 \pm 6.028$ \\
\hline 3rd molar to occlusal plane (angle), right & -0.720 & 38 & 0.476 & $-5.450 \pm 7.570$ \\
\hline 3rd molar to HRP (angle), right & -0.237 & 38 & 0.814 & $-1.325 \pm 5.595$ \\
\hline
\end{tabular}

Abbreviation: HRP, horizontal reference plane.

${ }^{a}$ Correlation significant at 0.05 level (two-tailed).

Statistically insignificant difference between the control and study groups were seen (- Tables $\mathbf{2}, \mathbf{3}$ ).

\section{Third Molar Angulation with Occlusal Plane}

The mean value for third molar angulation with $\mathrm{OP}$ was highest in the left side of study group $(122.95 \pm 11.157)$, followed by right side of study group (122.35 \pm 11.070$)$ and then in left side of control group $(120.85 \pm 17.977)$. The lowest mean was found in right side of control group (116.90 \pm 31.99$)$. Results showed statistically insignificant difference between the control and study groups (- Tables $\mathbf{2}, \mathbf{3}$ ).

\section{Third Molar Angulation with Horizontal Reference Plane}

The mean for third molar angulation with HRP was highest in left side of control group ( $45.27 \pm 20.59)$, followed by right side of study group ( $44.00 \pm 13.083)$ and then in right side of control group $(42.68 \pm 21.31)$. The lowest mean was found in left side of study group (39.550 \pm 12.701$)$. Student $t$-test showed statistically significant variation between control and study groups ( - Tables 2,3 ).

\section{Eruption Level}

Of the total 40 patients, $80 \%$ in the control group had eruption level B on right side and 65\% had eruption level B on left side, $20 \%$ and $35 \%$ patients had eruption level C, in right and left sides, respectively. In study group, 95\% and $85 \%$ patients had eruption level B on right and left sides, respectively. Five and $15 \%$ patients had eruption level $\mathrm{C}$ on right and left sides, respectively ( - Table 4 , - Fig. 6 ).

\section{Discussion}

The study of the mandibular third molar has always aroused great interest in clinical practice. The development of space for the third molar is affected by various factors, including backward slope of anterior border of ramus in relation to the alveolar border, resorption of bone from anterior border of ramus, forward movement of dentition, growth in length of the mandible, sagittal direction of mandibular growth, and sagittal direction of eruption of dentition. ${ }^{6}$

Third molar eruption can be anticipated at an early age during orthodontic treatment, and then later occurrences of difficult impactions can be avoided. During this time, the third molar bud is developing and undergoing important rotational preeruptive movements. ${ }^{11,12}$ The influence of the third molar on mandibular incisor crowding is evaluated in the dental literature and has been a challenging subject for many years. Therefore, 40 patients in this study with age group 
Table 4 Distribution of sample in control and study groups regarding eruption level

\begin{tabular}{|l|l|l|l|l|}
\hline \multirow{2}{*}{ Eruption level } & \multicolumn{2}{|c|}{ Control } & \multicolumn{2}{c|}{ Study } \\
\cline { 2 - 5 } & Right & Left & Right & Left \\
\hline Level B & $\begin{array}{l}16 \\
(80 \%)\end{array}$ & $\begin{array}{l}13 \\
(65 \%)\end{array}$ & $19(95 \%)$ & $17(85 \%)$ \\
\hline Level C & $4(20 \%)$ & $7(35 \%)$ & $1(5 \%)$ & $3(15 \%)$ \\
\hline
\end{tabular}

$\mathrm{B}$, partially erupted; $\mathrm{C}$, unerupted.
12 to 22 years with mean age of 15.40 years were selected to determine whether the variations in molars had any favorable or unfavorable effect on the mandibular incisor crowding.

The sample in this study was divided into two groups: control group ( $n=20$ ) with lower anterior crowding $<3 \mathrm{~mm}$ (minimal or no crowding) and the study group $(n=20)$ with lower anterior crowding of $>3 \mathrm{~mm}$ on the basis of Little's index of irregularity. Puneky et al (1984) found significant correlation $(r=0.84$, $p<0.001$ ) between irregularity index and space condition. ${ }^{13}$

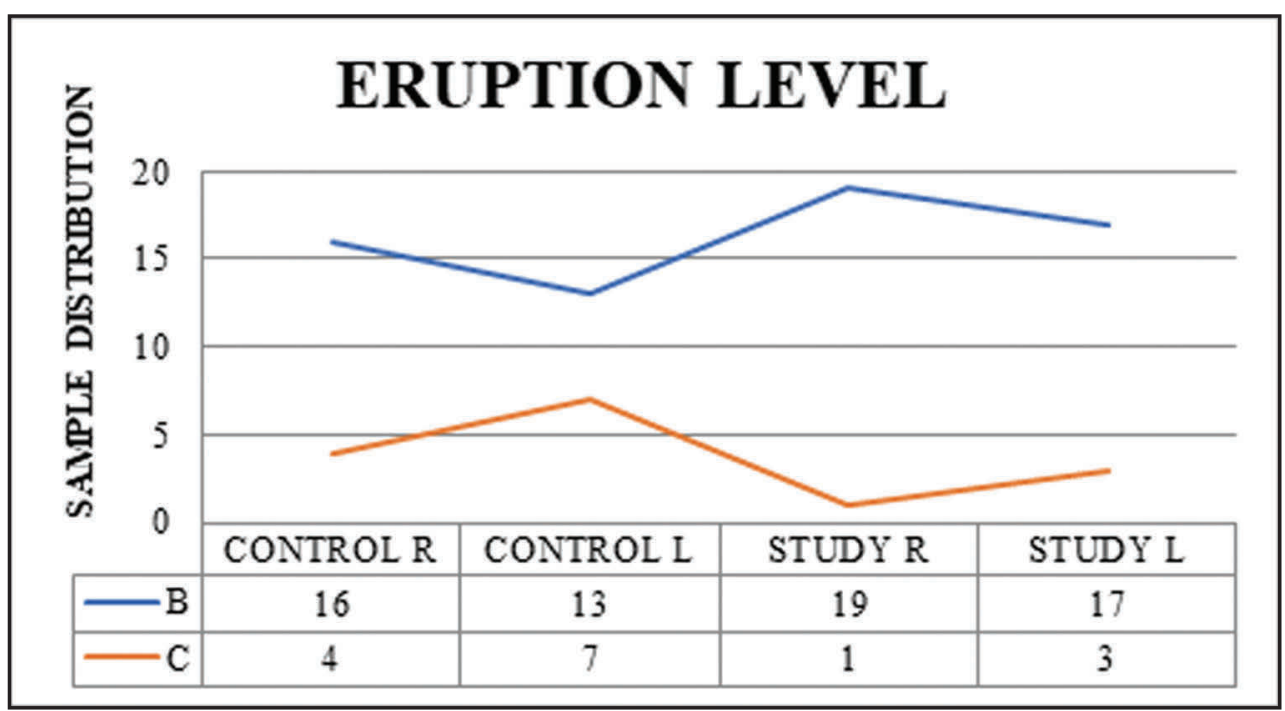

Fig. 6 Distribution of sample in control and study groups regarding eruption level. B: partially erupted; C: unerupted.

Third molar angulation measurements on lateral cephalograms as in previous studies by Artun (2005), Erdem (1998), and Capelli (1991) may be partial due to differences in angulation between superimposed contralateral images. ${ }^{14}$ Similar problems are present in any cephalometric study on changes in the posterior tooth positions and can only be avoided if measurements are made on 60-degree head films of right and left sides as depicted by Richardson (1978). ${ }^{12}$ However, OPGs have shown to be a unfailing indicator in evaluating third molar positions as shown by Olive and Basford (1981), ${ }^{15}$ Ganss et al (1993), ${ }^{8}$ and so they were used in this study.

In this study, when comparisons were made between the control and study groups, significant differences $(p=0.049)$ were noted in relation to third molar space on right side. It was seen that when the third molar space is less, the lower anterior crowding is more. Also, it was noticed that the molar crowding is more when eruption level of the third molar is between the OP and CEJ level of the neighboring second molar, that is, partially erupted. However, statistically insignificant differences were found for the third molar angulations between both the groups. Overall this study results depicted no clinically significant relation of the third molar to the mandibular incisor crowding.

The measurements used in this study were the Ganss ratio, ${ }^{8}$ given by Ganss et al (1993), ${ }^{8}$ previously used by Olive and Basford ${ }^{15}$ to evaluate space. If the ratio values are $>1,70 \%$ of teeth would gradually enter into the arch. Lower values indicated probability of impaction. ${ }^{8}$ Hence, it may be proposed that, if enough space is present for the third molar to erupt, tooth takes a normal position in the arch and does not exert any adverse effect on other teeth, whereas if space is inadequate, third molars may increase preexisting crowding. The variations occurring at low values of the Ganss ratio may be accounted for by the physics of force vectors. ${ }^{16}$

These findings strengthen those of the previous studies, which showed that the third molars have no clinically significant relation to the mandibular incisor crowding. Studies were conducted by Hasegawa et al $(2012)^{17}$ and Cherian and Ravi (2016) ${ }^{14}$ regarding Ganss ratio and third molar angulation. They concluded that there was insignificant correlation between lower anterior crowding and lower third molar angulation. The Ganss ratio calculations in their study showed that lower first and second molars and the second premolars are inclined mesially if there was insufficient space for the lower third molars. Buschang and Shulman (2003), ${ }^{18}$ Shanley (1962), ${ }^{19}$ and AI Balkhi et al (2004) $)^{20}$ concluded in their respective studies that third molars were not associated with crowding and significant greater crowding took place during adulthood which was in concordance with our study. Zachrisson $(2005)^{21}$ also denies a correlation between third molar eruption and anterior incisor crowding.

Dahlberg (1945) implied that last tooth to develop in each field is most variable in size and development. ${ }^{22,23}$ The irregular developmental path of third molars in humans and 
the great fluctuation in their path of eruption may justify absence of a significant correlation between angulations of this tooth, as depicted in this study.

Also, the authors Little et al (1981), ${ }^{24}$ Weinstein (1971), ${ }^{25}$ Björk and Skieller (1972), ${ }^{26}$ and Siatkowski (1974) ${ }^{27}$ propose there are multiple reasons of incisor crowding, but do not believe there is an relation with third molar eruption. There is a tendency for incisors to retrocline with age. Lower incisors might move under the forces of tongue and lip muscle contraction that may be responsible for increased crowding. Crowding became more severe in adolescents, young adults, or even later in life with no obvious cause. Lundström (1969), ${ }^{28}$ Harradine et al (1998), ${ }^{29}$ Ades et al $(1990),{ }^{30}$ and Lindauer et al $(2007)^{31}$ suggested that third molar removal with the objective of preventing mandibular incisor irregularity might be unjust.

Conversely, some authors concluded that third molar had a significant relation with mandibular incisor crowding. Bergström and Jensen (1961),,32 Vego (1962),,33 and Moorrees and Reed (1952) $)^{34}$ noted that there was greater crowding in the quadrants in which third molars were still present, than in those in which third molars were absent. Richardson (1979), ${ }^{35}$ (1989), ${ }^{36}$ and (1996) ${ }^{37}$ observed first molar drift and incisor crowding in patients with retained third molars. Lindquist and Thilander $(1982)^{38}$ stated extraction of the impacted third molars relieved anterior crowding.

Björk and Skieller (1972), ${ }^{26}$ while studying tooth eruption and facial development throughout adolescence, found no evidence to confirm a correlation between late lower labial segment crowding and third molar eruption. Kaplan (1974) ${ }^{39}$ and Bishara $(1999)^{40}$ expressed that there was no significant influence of third molars on the width and length of dental arches, and theory that third molars exert pressure on the teeth mesial to them could not be validated.

The role of the third molar still is a debatable issue despite multiple attempts to resolve its role in late anterior crowding. Further detailed studies are also required to assess correlation between lower anterior crowding and third molar eruption depth, angulation and space in different skeletal malocclusions, and also in different facial morphologies, including large sample size.

\section{Conclusions}

- Student's t-test showed significant difference for Ganss ratio in right side between control and study groups with $p=0.049$.

- Statistically insignificant difference for third molar angulations between control and study groups was observed.

- Study group showed more molars $95 \%$ on right side and $85 \%$ on left side in B level.

From this study, it can be concluded that no strong relation exists between the eruption level, eruption space and angulation of third molar, and the level of mandibular anterior crowding.

\section{Conflict of Interest}

None declared.

\section{References}

1 Bishara SE, Treder JE, Damon P, Olsen M. Changes in the dental arches and dentition between 25 and 45 years of age. Angle Orthod 1996;66(6):417-422

2 Richardson ME, Gormley JS. Lower arch crowding in the third decade. Eur J Orthod 1998;20(5):597-607

3 Almpani K, Kolokitha OE. Role of third molars in orthodontics. World J Clin Cases 2015;3(2):132-140

4 Bishara SE, Andreasen G. Third molars: a review. Am J Orthod 1983;83(2):131-137

5 Little RM. The irregularity index: a quantitative score of mandibular anterior alignment. Am J Orthod 1975;68(5):554-563

6 Hattab FN, Alhaija ES. Radiographic evaluation of mandibular third molar eruption space. Oral Surg Oral Med Oral Pathol Oral Radiol Endod 1999;88(3):285-291

7 Gohilot A, Pradhan T, Keluskar KM. Effects of first premolar extraction on maxillary and mandibular third molar angulation after orthodontic therapy. J Oral Biol Craniofac Res 2012;2(2):97-104

8 Ganss C, Hochban W, Kielbassa AM, Umstadt HE. Prognosis of third molar eruption. Oral Surg Oral Med Oral Pathol 1993;76(6):688-693

9 Jain S, Valiathan A. Influence of first premolar extraction on mandibular third molar angulation. Angle Orthod 2009;79(6):1143-1148

10 Pell GJ, Gregory BT. Impacted mandibular third molars: classification and modified techniques for removal. Dent Dig 1933;39:330-338

11 Silling G. Development and eruption of the mandibular third molar and its response to orthodontic therapy. Angle Orthod 1973;43(3):271-278

12 Richardson M. Pre-eruptive movements of the mandibular third molar. Angle Orthod 1978;48(3):187-193

13 Puneky PJ, Sadowsky C, BeGole EA. Tooth morphology and lower incisor alignment many years after orthodontic therapy. Am J Orthod 1984;86(4):299-305

14 Cherian M, Ravi M. Lower third molar space and angulation in individuals with lower anterior crowding. Nitte University Journal of Health Science. 2016;6(3):10-15

15 Olive RJ, Basford KE. Transverse dento-skeletal relationships and third molar impaction. Angle Orthod 1981;51(1):41-47

16 Niedzielska I. Third molar influence on dental arch crowding. Eur J Orthod 2005;27(5):518-523

17 Hasegawa Y, Terada K, Kageyama I, Tsuchimochi T, Ishikawa F, Nakahara S. Influence of third molar space on angulation and dental arch crowding. Odontology 2013;101(1):22-28

18 Buschang $\mathrm{PH}$, Shulman JD. Incisor crowding in untreated persons 15-50 years of age: United States, 1988-1994. Angle Orthod 2003;73(5):502-508

19 Shanley LS. The influence of mandibular third molars on mandibular anterior teeth. Am J Orthod 1962;48:786-787

20 AI Balkhi, KM. The effect of different lower third molar conditions on the re-crowding of lower anterior teeth in the absence of tight inter proximal contacts one year post orthodontic treatment: a pilot study. J Contemp Dent Pract 2004;15:66-73

21 Zachrisson BU. Mandibular third molars and late lower arch crowding-the evidence base. World J Orthod 2005;6(2):180-186

22 Dahlberg AA. The changing dentition of the man. J Am Dent Assoc 1945;32:676-690 
23 Sofaer JA, Bailit HL, MacLean CJ. A developmental basis for differential tooth reduction during hominid evolution. Evolution 1971;25(3):509-517

24 Little RM, Wallen TR, Riedel RA. Stability and relapse of mandibular anterior alignment-first premolar extraction cases treated by traditional edgewise orthodontics. Am J Orthod 1981;80(4):349-365

25 Weinstein S. Third molar implications in orthodontics. J Am Dent Assoc 1971;82(4):819-823

26 Björk A, Skieller V. Facial development and tooth eruption. An implant study at the age of puberty. Am J Orthod 1972;62(4):339-383

27 Siatkowski RE. Incisor uprighting: mechanism for late secondary crowding in the anterior segments of the dental arches. Am J Orthod 1974;66(4):398-410

28 Lundström A. Changes in crowding and spacing of the teeth with age. Dent Pract Dent Rec 1969;19(6):218-224

29 Harradine NW, Pearson MH, Toth B. The effect of extraction of third molars on late lower incisor crowding: a randomized controlled trial. Br J Orthod 1998;25(2):117-122

30 Amin AG, Joondeph DR, Little RM, Chapko MK. A long term study of the relationship of the third molars to changes in the mandibular dental arch. Am J Orthod Dentofacial Orthop 1990;97:323-335

31 Lindauer SJ, Laskin DM, Tüfekçi E, Taylor RS, Cushing BJ, Best AM. Orthodontists' and surgeons' opinions on the role of third molars as a cause of dental crowding. Am J Orthod Dentofacial Orthop 2007;132(1):43-48
32 Bergström K, Jensen R. Responsibility of the third molar for secondary crowding. Dent Abstr 1961;6:544

33 Vego L. A longitudinal study of mandibular arch perimeter. Angle Orthod 1962;32:187-192

34 Moorrees CFA, Reed RB. Biometrics of crowding and spacing of the teeth in the mandible. Am J Phys Anthropol 1954;12(1):77-88

35 Richardson ME. Late lower arch crowding facial growth or forward drift? Eur J Orthod 1979;1(4):219-225

36 Richardson ME. The role of the third molar in the cause of late lower arch crowding: a review. Am J Orthod Dentofacial Orthop 1989;95(1):79-83

37 Richardson ME. Orthodontic implications of lower third molar development. Dent Update 1996;23(3):96-102

38 Lindqvist B, Thilander B. Extraction of third molars in cases of anticipated crowding in the lower jaw. Am J Orthod 1982;81(2):130-139

39 Kaplan RG. Mandibular third molars and postretention crowding. Am J Orthod 1974;66(4):411-430

40 Bishara SE. Third molars: a dilemma! Or is it? Am J Orthod Dentofacial Orthop 1999;115(6):628-633 